\title{
Comprehensive HIV/AIDS knowledge and HIV testing among men in sub-Saharan Africa: a multilevel modelling
}

\author{
Justice Kanor Tetteh ${ }^{1 \star(D)}$, James Boadu Frimpong ${ }^{2}$ (iD, Eugene Budu ${ }^{1}$, Collins $\mathrm{Adu}^{3}$ (iD, \\ Aliu Mohammed ${ }^{2}$ (D), Bright Opoku Ahinkorah ${ }^{4}$ and Abdul-Aziz Seidu ${ }^{1,5,6,7}$ (D)

\begin{abstract}
${ }^{1}$ Department of Population and Health, University of Cape Coast, Cape Coast, Ghana, ${ }^{2}$ Department of Health, Physical Education and Recreation, University of Cape Coast, Cape Coast, Ghana, ${ }^{3}$ Department of Health Promotion, Education and Disability Studies, Kwame Nkrumah, University of Science and Technology, Kumasi, Ghana, ${ }^{4}$ School of Public Health, Faculty of Health, University of Technology Sydney, Sydney, Australia, ${ }^{5}$ College of Public Health, Medical and Veterinary Sciences, James Cook University, Australia, ${ }^{6}$ Department of Estate Management, Takoradi Technical University, Takoradi, Ghana and ${ }^{7}$ Centre for Gender and Advocacy, Takoradi Technical University, Takoradi, Ghana *Corresponding author. Email: justice.tetteh@stu.ucc.edu.gh
\end{abstract}

(Received 3 February 2021; revised 26 August 2021; accepted 27 August 2021; first published online 05 November 2021)

\begin{abstract}
This study investigated the association between comprehensive HIV/AIDS knowledge and HIV testing among men in sub-Saharan Africa (SSA). Data were taken from the most recent (2010-2019) Demographic and Health Survey men's recode files of 29 countries in SSA. A total of 104,398 men who had complete information on all the variables of interest were included in the study. The outcome variable was HIV testing. A multilevel logistic regression analysis was conducted to determine the association between comprehensive HIV/AIDS knowledge and HIV testing. The results of the fixed effects model were presented as adjusted odds ratios (AORs) with $95 \%$ confidence intervals (CIs). The average prevalences of HIV testing and comprehensive HIV/AIDS knowledge among men in SSA were 53.5\% and 50.8\% respectively. Rwanda and Niger recorded the highest (93.6\%) and lowest prevalences (9.8\%) respectively. The prevalence of comprehensive HIV/AIDS knowledge among men in the 29 countries was $50.8 \%$, with the highest in Rwanda (76.4\%) and the lowest in Benin (31.1\%). Men who had no comprehensive HIV/ AIDS knowledge were less likely to test for HIV compared with those who had comprehensive HIV/AIDS knowledge ( $\mathrm{AOR}=0.59$, CI: $0.57-0.60$ ). Men who were older than 20 years, married or cohabiting, with at least secondary education, in the richest wealth quintile, exposed to mass media, used condoms and with multiple sexual partners were more likely to test for HIV. To improve HIV testing among men in SSA, this study recommends that policymakers and stakeholders step up comprehensive HIV/AIDS knowledge sensitization and education using effective tools such as mass media.
\end{abstract}

Keywords: HIV/AIDS; HIV testing; Sub-Saharan Africa

\section{Introduction}

HIV/AIDS remains a major public health threat despite the significant decline in AIDS-related deaths worldwide (Frank et al., 2019). As of 2019, there were an estimated 38.0 million people worldwide living with HIV/AIDS, with the highest percentage in sub-Saharan Africa (SSA) (World Health Organization [WHO], 2020). Approximately 1.7 million new HIV infections and 690,000 AIDS-related deaths occurred in 2019 (WHO, 2020). A recent report on the impact

\footnotetext{
(c) The Author(s), 2021. Published by Cambridge University Press. This is an Open Access article, distributed under the terms of the Creative Commons Attribution licence (https://creativecommons.org/licenses/by/4.0/), which permits unrestricted re-use, distribution, and reproduction in any medium, provided the original work is properly cited.
} 
of the COVID-19 pandemic on antiretroviral therapy (ART) suggests a possible disruption in HIV/AIDS management, which is expected to increase AIDS-related deaths in the next year, mostly in SSA. This has resulted in the need to scale up HIV/AIDS-related interventions to help curb the pandemic in the face of the COVID-19 threat (Jewell et al., 2020; WHO, 2020).

Globally, several interventions or programmes are being implemented to end the HIV/AIDS pandemic (Fauci \& Lane, 2020). In 2016, for instance, the United Nations Political Declaration on HIV/AIDS set a global target of accelerating the fight against HIV and ending the AIDS pandemic by 2030 (United Nations General Assembly, 2016). Among the targets of the United Nations Program on HIV/AIDS (UNAIDS) is to achieve $95-95-95$ by 2030 - that is, to diagnose at least 95\% of people living with HIV, of whom at least $95 \%$ should be on treatment and out of which at least $95 \%$ should have achieved viral suppression by 2030 (Pandey \& Galvani, 2019). However, a recent report shows that most countries are likely to miss the 2030 global target (Frank et al., 2019), largely due to gaps in HIV testing and treatment initiation (UNAIDS, 2018). Early initiation of treatment significantly decreases viral load and its associated morbidity and mortality (Cohen et al., 2011).

HIV counselling and testing is the first and most important step towards prevention and early initiation of treatment (Cohen et al., 2011; Sharma et al., 2015). However, it has been reported that about 9.4 million people living with HIV in 2017 did not know their status and a significant proportion of these people live in SSA (UNAIDS, 2018). Despite the significant improvement in voluntary HIV counselling, testing and HIV prevention measures, including the introduction of rapid diagnostic tests and self-tests (WHO, 2020), coverage remains low in most sub-Saharan African countries (Sharma et al., 2015; Harichund et al., 2019). Apart from discrimination, stigma and non-confidential testing environments (Bwambale et al., 2008; Harichund \& Moshabela, 2018), lack of comprehensive HIV/AIDS knowledge remains one of the major barriers to uptake of HIV testing in SSA (Aderemi et al., 2014; Harichund \& Moshabela, 2018). For example, in a cross-sectional survey to determine HIV testing uptake among youths in SSA, Asaolu et al. (2016) reported that having comprehensive HIV knowledge is associated with higher odds of being tested. Seidu et al. (2020) also reported that having comprehensive HIV/AIDS knowledge is associated with lower odds of self-reported sexually transmitted infections among sexually active men in SSA.

With the introduction of community and home-based HIV counselling and testing models, the uptake of HIV testing among males in SSA has been boosted (DiCarlo et al., 2014; Hensen et al., 2015). Available evidence suggests that most studies on comprehensive HIV/AIDS knowledge and testing in SSA have focused on women (e.g. Teshome et al., 2016; Yaya et al., 2016; Sheikh et al., 2017; Darteh, 2020), students (e.g. Agha, 2012; Asante, 2013 Oljira et al., 2013; Kejela et al., 2015), youth or adolescents (e.g. Ziraba et al., 2011; Asaolu et al., 2016; Chikwari et al., 2018) and men who have sex with men (e.g. Sorensen et al., 2012). Thus, there is a paucity of literature on the association between comprehensive HIV/AIDS knowledge and testing among the general male population in SSA. Therefore, this study focuses generally on the association between comprehensive HIV/AIDS knowledge and HIV testing among men in SSA. Understanding the association between comprehensive HIV/AIDS knowledge and HIV testing is important in identifying targeted areas for HIV/AIDS education and testing strategies that could potentially increase HIV testing uptake among men in SSA and contribute to the realization of the global HIV/AIDS target of $95-95-95$ by 2030 .

\section{Methods}

\section{Theoretical model}

The study was guided by the Knowledge, Attitude and Practice (KAP) survey model adapted from Muleme et al. (2017). This model states that an individual's knowledge could be influenced by socio-demographic factors that affect their attitude, which then becomes an incentive or a 


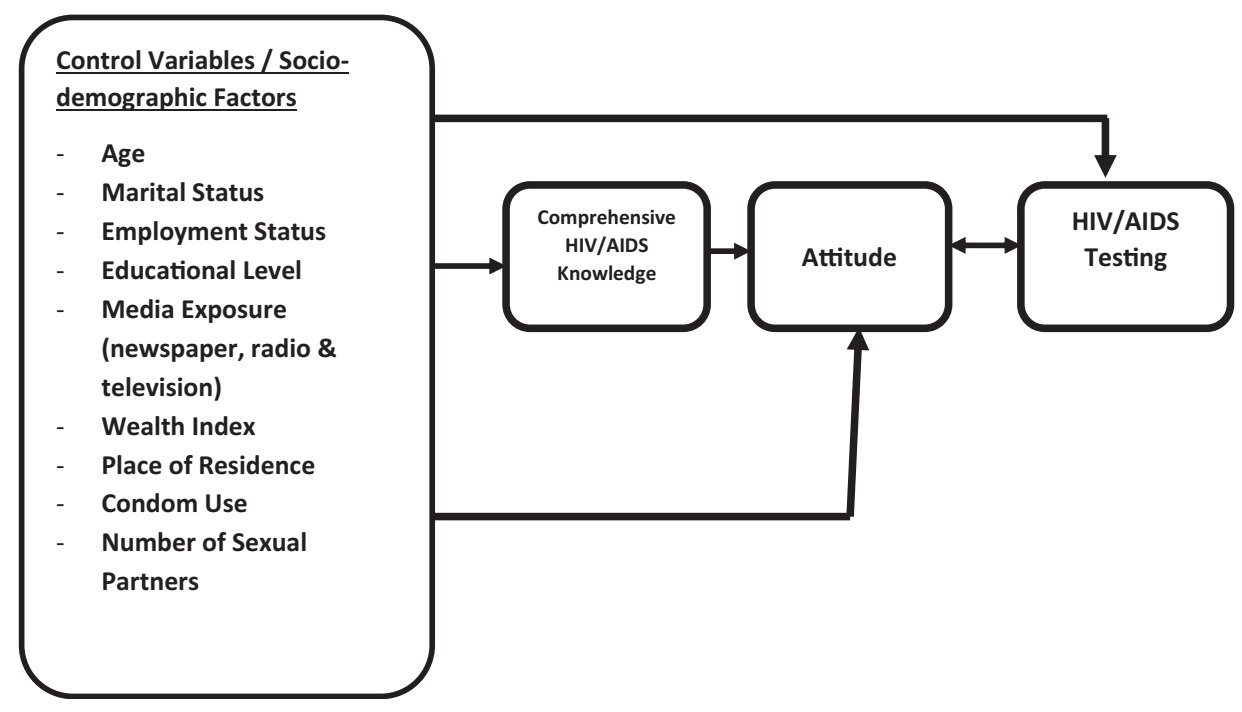

Figure 1. Knowledge, attitude and practice theoretical model; adapted from Muleme et al. (2017).

disincentive to practice (behaviour). The assumption here, based on previous studies (Asaolu et al., 2016; Seidu et al., 2020), was that those with comprehensive HIV/AIDS knowledge would be more likely to test for their HIV/AIDs status. Furthermore, it was recognized that comprehensive HIV/AIDS knowledge and testing could be influenced by socio-demographic factors, including age, marital status, employment status, educational level, exposure to newspapers, exposure to radio, exposure to television, wealth index, place of residence, condom use and multiple sexual partners, as reported in the literature (Ziraba et al., 2011; Agha, 2012; Teshome et al., 2016; Yaya et al., 2016; Agegnehu et al., 2020; Kefale et al., 2020). Figure 1 shows the theoretical associations between the outcome, independent and control variables employed in the study.

\section{Data source}

The study used data from the most recent (2010-2019) Demographic and Health Surveys (DHS) of 29 sub-Saharan African countries - specifically, the men's recode files. The DHS is a nationally representative survey conducted in over 85 low- and middle-income countries. It focuses on essential markers, including breastfeeding, fertility, family planning, immunization, HIV/AIDS, child health and nutrition (Corsi et al., 2012). The survey employs a two-stage stratified sampling technique, which makes the data nationally representative. The study by Aliaga and Ruilin (2006) provides details of the sampling process. A total of 104,398 men who had complete information on all the variables of interest were included in the current study. The Strengthening the Reporting of Observational Studies in Epidemiology' (STROBE) statement was consulted during the writing of the manuscript (Von Elm et al., 2014). The dataset is freely available for download at: https://dhsprogram.com/data/available-datasets.cfm.

\section{Definition of variables}

\section{Outcome variable}

The outcome variable was HIV testing, which was derived from the question 'Have you ever tested for HIV?' Responses were 'Yes' and 'No', coded as 'No' $=0$ and 'Yes' $=1$. 


\section{Explanatory variable}

Comprehensive HIV/AIDS knowledge was used as the main explanatory variable. This was defined as knowing that consistent use of condoms during sexual intercourse, and having just one uninfected faithful partner, can reduce the chance of getting an HIV infection; knowing that a healthy-looking person can have the AIDS virus; and rejecting the two most common local misconceptions about AIDS transmission or prevention (i.e. via mosquito bites or witchcraft/supernatural means). Comprehensive HIV knowledge was dichotomously coded 'Yes' $=1$ and 'No' $=0$. An index was created based on the correct answers to the preceding questions (Darteh, 2020; Frimpong et al., 2021).

\section{Control variables}

Eleven control variables were considered in the study, broadly grouped into individual level and contextual level variables. The individual level variables included age, employment status, marital status, educational level, exposure to newspapers, exposure to radio, exposure to television, condom use and number of sexual partners. The contextual level factors included wealth quintile and type of place of residence. These variables were not determined a priori; instead, they were based on parsimony, theoretical relevance and practical significance with HIV testing (Yaya et al., 2016; Agegnehu et al., 2020; Kefale et al., 2020).

\section{Statistical analyses}

The data were analysed with Stata version 14.0. The analysis was done in three steps. The first step was the graphical computation of the prevalence of HIV testing and comprehensive HIV/AIDS knowledge among men in SSA. The second step was a bivariate analysis, which calculated the proportions of HIV testing across the explanatory and control variables with their significance levels (Table 1). To check for a high correlation among the explanatory and control variables, a test for multicollinearity was carried out using the variance inflation factor (VIF) and the results showed no evidence of high collinearity (Mean VIF $=1.41$, Maximum VIF $=1.69$, and Minimum $\mathrm{VIF}=1.06$ ).

All the variables that showed statistical significance from the Table 1 were moved to a multilevel logistic regression analysis. Five models were used to present the results (Model 0, Model I, Model II, Model III, Model IV). Model 0 was the empty model that had no explanatory or control variables. Model I had only the key explanatory variable. Model II had the individual-level control variables. Model III had the contextual-level control variables. Model IV had the explanatory variable and all the control variables. However, the results for Models 0, I and IV are presented. The multilevel logistic regression analysis comprised fixed effects and random effects (Austin \& Merlo, 2017). The results of the fixed effects of the models were presented as Adjusted Odds Ratios (AORs) while the random effects were assessed with intra-cluster correlation (ICC) (Merlo et al., 2016). Model comparison was done using the log-likelihood ratio (LLR) and Akaike's Information Criterion (AIC) test. The highest log-likelihood and the lowest AIC were used to determine the best-fit model (see Table 2). All frequency distributions were weighted (v005/ 1000000) while the survey command svy in Stata was used to adjust for the complex sampling structure of the data in the regression analyses.

\section{Results}

Figure 2 presents the prevalence of HIV testing among men in the 29 sub-Saharan African countries. On the average, the prevalence of HIV testing was 53.5\% in SSA. Rwanda and Niger recorded the highest (93.6\%) and lowest prevalences (9.8\%) respectively. The prevalence of comprehensive HIV/AIDS knowledge among men in the 29 countries was $50.8 \%$, with the highest in Rwanda (76.4\%) and the lowest in Benin (31.1\%) (Figure 3). 
Table 1. Description of study sample

\begin{tabular}{|c|c|c|c|}
\hline Country & Survey years & Weighted $n$ & Weighted \% \\
\hline Burkina Faso & 2010 & 4753 & 4.55 \\
\hline Benin & $2017-18$ & 4038 & 3.87 \\
\hline Burundi & $2016-17$ & 4205 & 4.03 \\
\hline Congo DR & $2013-14$ & 5097 & 4.88 \\
\hline Congo & 2011-12 & 3558 & 3.41 \\
\hline Cote D'Ivoire & 2011-12 & 2877 & 2.76 \\
\hline Cameroon & 2011 & 4136 & 3.96 \\
\hline Ethiopia & 2008 & 6309 & 6.04 \\
\hline Gabon & 2012 & 3730 & 3.57 \\
\hline Ghana & 2014 & 2701 & 2.59 \\
\hline Gambia & 2013 & 1526 & 1.46 \\
\hline Guinea & 2018 & 1611 & 1.54 \\
\hline Kenya & 2014 & 8758 & 8.41 \\
\hline Comoros & 2012 & 1302 & 1.03 \\
\hline Mali & 2018 & 2523 & 2.42 \\
\hline Malawi & $2015-16$ & 5319 & 5.09 \\
\hline Mozambique & 2015 & 3325 & 3.18 \\
\hline Niger & 2013 & 1965 & 1.88 \\
\hline Namibia & 2013 & 2701 & 2.59 \\
\hline Rwanda & 2014-15 & 3612 & 3.47 \\
\hline Sierra Leone & 2013 & 3665 & 3.51 \\
\hline Senegal & $2010-11$ & 1929 & 1.85 \\
\hline Chad & 2014-15 & 1742 & 1.67 \\
\hline Togo & 2013-14 & 2632 & 2.52 \\
\hline Uganda & 2016 & 3419 & 3.28 \\
\hline Zambia & 2018-19 & 8004 & 7.67 \\
\hline Zimbabwe & 2015 & 5263 & 5.04 \\
\hline
\end{tabular}

Table 2 presents the prevalences of HIV testing by the explanatory and control variables. The majority (62.5\%) of men who had comprehensive knowledge of HIV/AIDS presented themselves for testing compared with only $44.3 \%$ of men who had no comprehensive HIV/ AIDS knowledge. HIV testing was highest among men in the age group 30-34 (59.4\%), those who were not working (54.3\%) and who were cohabiting (55.6\%). Men with secondary education (61.3\%), the richest (65.6\%), those residing in urban areas $(59.7 \%)$, those exposed to newspapers almost every day (82.3\%), those exposed to radio almost every day $(81.4 \%)$, and those exposed to television almost every day $(72.6 \%)$ had the highest proportions of HIV testing. Men who used condoms and those who had multiple sexual partners had slightly higher proportions testing for HIV (60.9\% and $60.8 \%$ respectively). 
Table 2. HIV testing by explanatory variables ( $N=104,398$ weighted)

\begin{tabular}{|c|c|c|c|c|}
\hline Variable & Weighted $n$ & Weighted \% & HIV testing & $p$-value \\
\hline Comprehensive HIV/AIDS knowledge & & & & $<0.001$ \\
\hline No & 48,511 & 49.3 & 44.3 & \\
\hline Yes & 55,887 & 50.7 & 62.5 & \\
\hline Age (years) & & & & $<0.001$ \\
\hline $15-19$ & 7933 & 7.6 & 32.4 & \\
\hline $20-24$ & 15,357 & 14.7 & 51.5 & \\
\hline $25-29$ & 17,735 & 17.0 & 58.8 & \\
\hline $30-34$ & 16,721 & 16.0 & 59.4 & \\
\hline $35-39$ & 14,571 & 14.0 & 56.8 & \\
\hline $40-44$ & 12,050 & 11.5 & 56.2 & \\
\hline $45-49$ & 9314 & 8.9 & 52.0 & \\
\hline $50-54$ & 6703 & 6.4 & 51.1 & \\
\hline $55+$ & 4015 & 3.9 & 43.1 & \\
\hline Employment status & & & & $<0.001$ \\
\hline Working & 9319 & 8.9 & 45.3 & \\
\hline Not working & 95,079 & 91.1 & 54.3 & \\
\hline Marital status & & & & $<0.001$ \\
\hline Not married & 25,774 & 24.7 & 47.4 & \\
\hline Married & 61,909 & 59.3 & 55.2 & \\
\hline Cohabiting & 12,645 & 12.1 & 55.6 & \\
\hline Other & 4071 & 3.9 & 60.1 & \\
\hline Educational level & & & & $<0.001$ \\
\hline No education & 19,501 & 18.7 & 25.4 & \\
\hline Primary & 32,773 & 31.4 & 57.9 & \\
\hline Secondary+ & 52,124 & 49.9 & 61.3 & \\
\hline Wealth Index & & & & $<0.001$ \\
\hline Poorest & 15,548 & 18.9 & 41.4 & \\
\hline Poorer & 18,667 & 17.9 & 46.4 & \\
\hline Middle & 20,084 & 19.2 & 51.2 & \\
\hline Richer & 22,821 & 21.9 & 56.2 & \\
\hline Richest & 27,277 & 26.1 & 65.6 & \\
\hline Place of residence & & & & $<0.001$ \\
\hline Urban & 43,232 & 41.4 & 59.7 & \\
\hline Rural & 61,166 & 58.6 & 49.2 & \\
\hline Exposure to newspapers & & & & $<0.001$ \\
\hline Not at all & 64,469 & 61.8 & 45.5 & \\
\hline
\end{tabular}


Table 2. (Continued)

\begin{tabular}{|c|c|c|c|c|}
\hline Variable & Weighted $n$ & Weighted \% & HIV testing & $p$-value \\
\hline Less than once a week & 17,888 & 17.1 & 62.9 & \\
\hline At least once a week & 20,563 & 19.7 & 68.4 & \\
\hline Almost every day & 1478 & 1.4 & 82.3 & \\
\hline Exposure to radio & & & & $<0.001$ \\
\hline Not at all & 22,438 & 21.5 & 44.2 & \\
\hline Less than once a week & 19,228 & 18.4 & 49.8 & \\
\hline At least once a week & 58,371 & 55.9 & 56.3 & \\
\hline Almost every day & 4361 & 4.2 & 81.4 & \\
\hline Exposure to television & & & & $<0.001$ \\
\hline Not at all & 44,382 & 42.5 & 45.9 & \\
\hline Less than once a week & 18,223 & 17.5 & 43.4 & \\
\hline At least once a week & 36,299 & 34.8 & 60.0 & \\
\hline Almost every day & 5494 & 5.3 & 72.6 & \\
\hline Condom use & & & & $<0.001$ \\
\hline No & 80,541 & 77.1 & 51.3 & \\
\hline Yes & 23,857 & 22.9 & 60.9 & \\
\hline Multiple sexual partners & & & & $<0.001$ \\
\hline No & 64,661 & 61.9 & 54.6 & \\
\hline Yes & 39,737 & 38.1 & 61.8 & \\
\hline
\end{tabular}

\section{Multilevel logistic regression results on determinants of HIV testing among men in sub-Saharan Africa}

Fixed effects results

Table 3 presents the multilevel logistic regression results on the determinants of HIV testing among men in SSA. Men who had no comprehensive HIV/AIDS knowledge were less likely to test for HIV compared with their counterparts who had comprehensive HIV/AIDS knowledge $(\mathrm{AOR}=0.59, \mathrm{CI}: 0.57-0.60)$ With the covariates, age, employment status, marital status, educational level, wealth index, exposure to newspapers, exposure to radio, exposure to television, condom use, having multiple sexual partners, and place of residence were associated with HIV testing (Model IV).

\section{Random effects results}

The random effects results indicated a substantial variation in HIV testing among men in SSA across the PSUs without the explanatory and control variables, as shown in Model 0 $\left(\sigma^{2}=0.35 ; 95 \% \mathrm{CI}=0.30-0.41\right)$. The ICC value showed that about $10 \%(\mathrm{ICC}=0.09)$ of the total variance was attributable to the clustering at the contextual level. The variations changed with the inclusion of key explanatory, individual and community level variables, and all explanatory variables. The AIC values showed variations in model fitness from one model to another. However, the final model, which had all the explanatory variables, was considered the best-fit model since it had the lowest AIC (Table 3). 


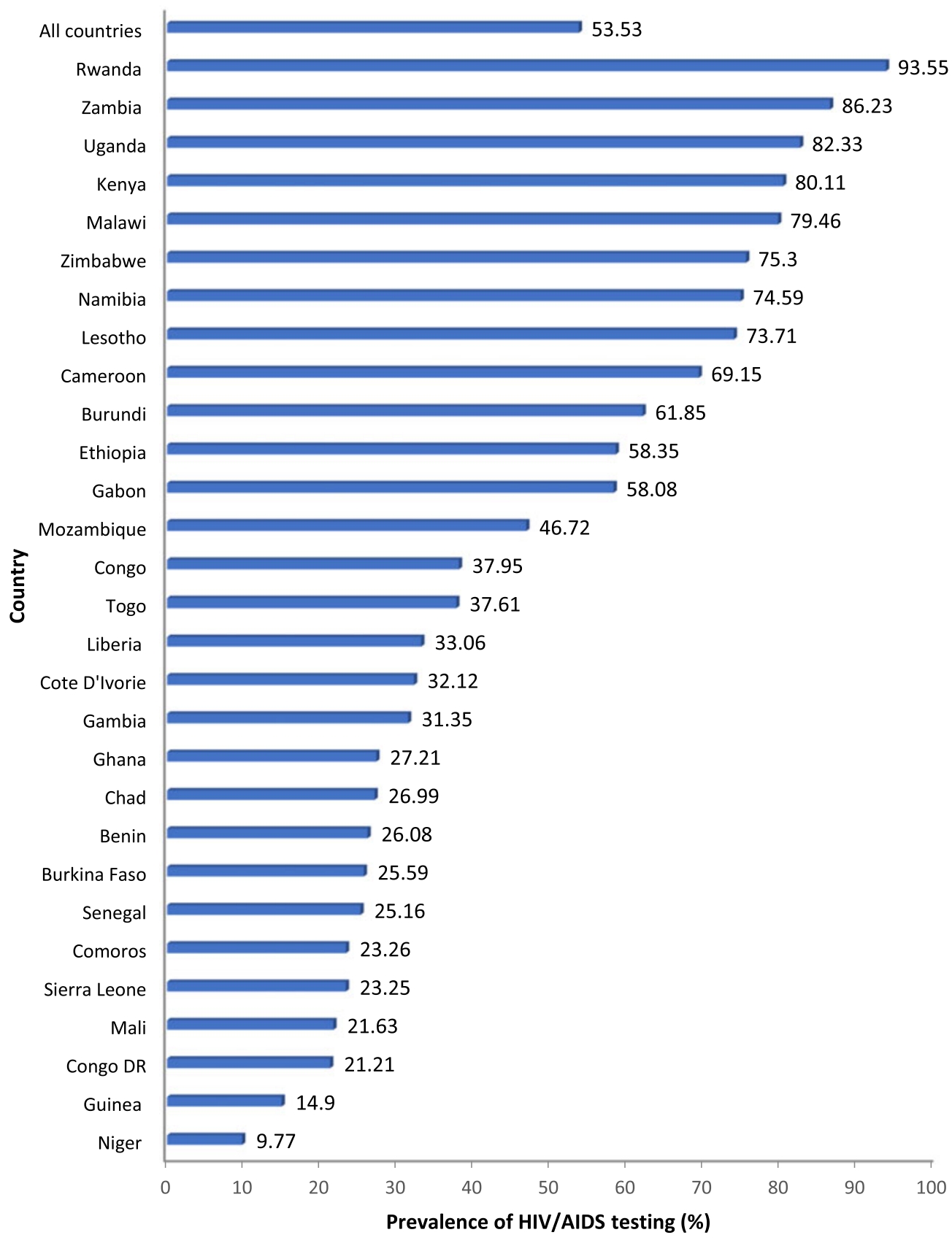

Figure 2. Prevalences of HIV testing among men in 29 countries in sub-Saharan Africa.

\section{Discussion}

This study investigated the association between comprehensive HIV and AIDS knowledge and HIV testing among men in 29 sub-Saharan African countries using DHS data. The prevalences of comprehensive HIV/AIDS knowledge and HIV testing among men in SSA were found to be $50.3 \%$ and $53.5 \%$, respectively, which are lower than the UNAIDS target of $95 \%$ by 2030 


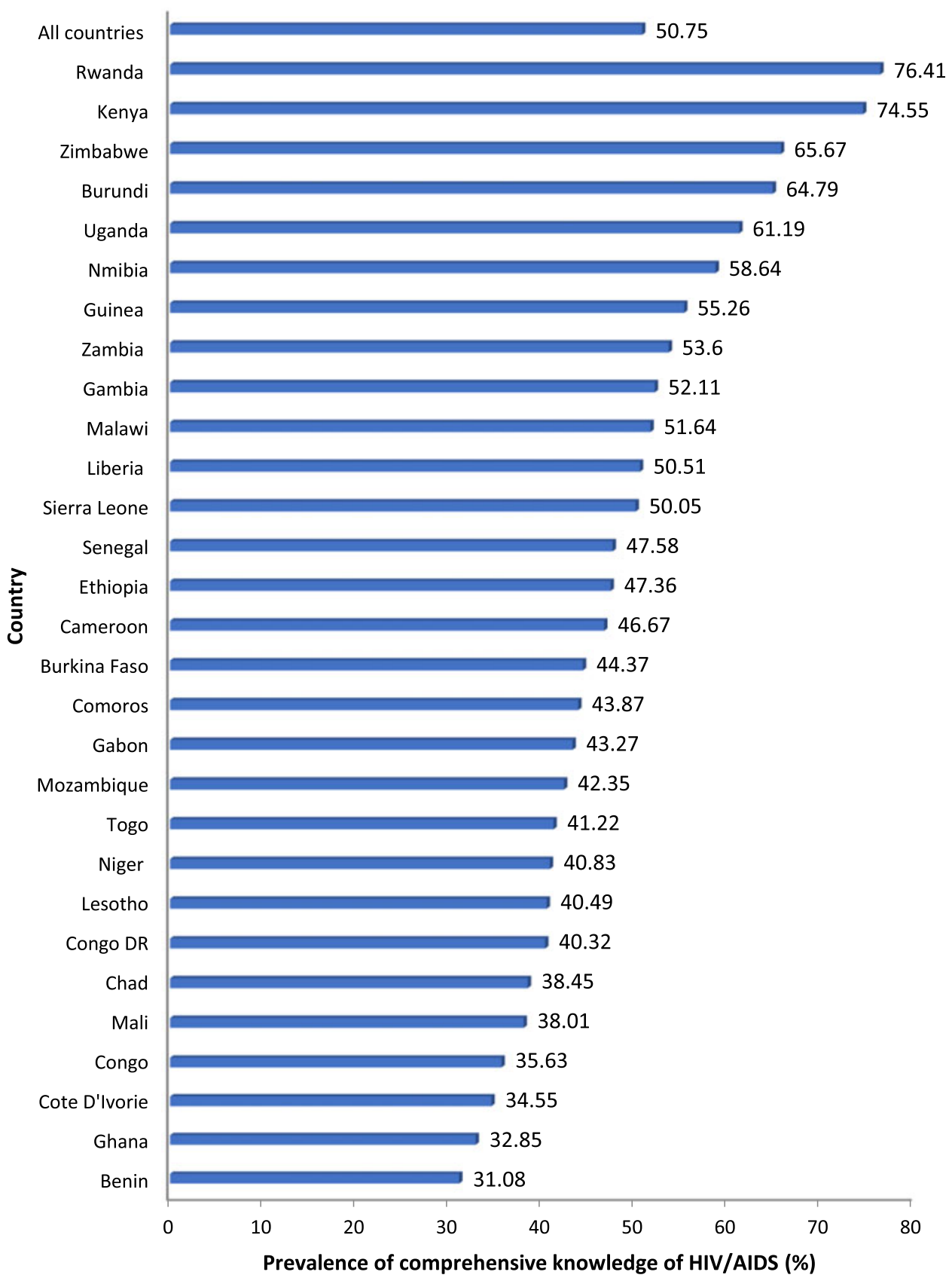

Figure 3. Prevalences of comprehensive knowledge of HIV/AIDS among men in 29 countries in sub-Saharan Africa.

(United Nations General Assembly, 2016). The study also found that comprehensive HIV/AIDS knowledge, age, employment status, marital status, educational level, wealth index, exposure to newspapers, exposure to radio, exposure to television, condom use, having multiple sexual partners and place of residence were associated with HIV testing.

The finding that Rwanda, Uganda, Kenya, and Malawi recording the highest prevalences of HIV testing among men in SSA, and Niger, Guinea, Congo DR, and Mali recorded the lowest 
Table 3. Multilevel logistic regression results on the determinants of HIV testing among men in sub-Saharan Africa

\begin{tabular}{|c|c|c|}
\hline Variable & Model 0 & Model IV \\
\hline \multicolumn{3}{|c|}{ Comprehensive HIV/AIDS knowledge } \\
\hline No & $0.47^{\star \star \star}(0.46-0.48)$ & $0.59^{\star \star \star}(0.57-0.60)$ \\
\hline Yes (Ref.) & 1 & \\
\hline \multicolumn{3}{|l|}{ Age (years) } \\
\hline $15-19$ & & $0.39^{\star \star \star}(0.36-0.42)$ \\
\hline $20-24$ & & $0.77^{\star \star \star}(0.73-0.81)$ \\
\hline \multicolumn{3}{|l|}{ 25-29 (Ref.) } \\
\hline $30-34$ & & $1.01(0.96-1.06)$ \\
\hline $35-39$ & & $0.91^{\star \star \star}(0.82-0.91)$ \\
\hline $40-44$ & & $0.86^{\star \star \star}(0.82-0.91)$ \\
\hline $45-49$ & & $0.77^{\star \star \star}(0.73-0.82)$ \\
\hline $50-54$ & & $0.76^{\star \star \star}(0.72-0.81)$ \\
\hline $55+$ & & $0.63^{\star \star *}(0.58-0.68)$ \\
\hline \multicolumn{3}{|l|}{ Employment status } \\
\hline Working & & $0.84^{\star \star \star}(0.80-0.88)$ \\
\hline \multicolumn{3}{|l|}{ Not working (Ref.) } \\
\hline \multicolumn{3}{|l|}{ Marital status } \\
\hline Not married & & $0.56^{\star \star \star}(0.53-0.60)$ \\
\hline \multicolumn{3}{|l|}{ Married (Ref.) } \\
\hline Cohabiting & & $0.89^{\star \star \star}(0.85-0.93)$ \\
\hline Other & & $0.87^{\star \star \star}(0.80-0.94)$ \\
\hline \multicolumn{3}{|l|}{ Educational level } \\
\hline No education & & $0.30^{\star \star *}(0.29-0.31)$ \\
\hline Primary & & $1.08^{\star \star \star}(1.05-1.12)$ \\
\hline \multicolumn{3}{|l|}{ Secondary+ (Ref.) } \\
\hline \multicolumn{3}{|l|}{ Exposure to newspapers } \\
\hline \multicolumn{3}{|l|}{ Not at all (Ref.) } \\
\hline Less than once a week & & $1.29^{\star \star \star}(1.24-1.34)$ \\
\hline At least once a week & & $1.44^{\star \star \star}(1.38-1.50)$ \\
\hline Almost every day & & $2.05^{\star \star \star}(1.72-2.43)$ \\
\hline \multicolumn{3}{|l|}{ Exposure to radio } \\
\hline \multicolumn{3}{|l|}{ Not at all (Ref.) } \\
\hline Less than once a week & & $1.00(0.96-1.05)$ \\
\hline At least once a week & & $1.05^{\star \star \star}(1.01-1.09)$ \\
\hline Almost every day & & $2.71^{\star \star \star}(2.47-2.98)$ \\
\hline
\end{tabular}


Table 3. (Continued)

\begin{tabular}{|c|c|c|c|}
\hline Variable & Model 0 & Model I & Model IV \\
\hline \multicolumn{4}{|l|}{ Exposure to television } \\
\hline \multicolumn{4}{|l|}{ Not at all (Ref.) } \\
\hline Less than once a week & & & $1.14^{\star \star \star}(1.10-1.19)$ \\
\hline At least once a week & & & $1.15^{\star \star \star}(1.11-1.20)$ \\
\hline Almost every day & & & $1.39^{\star \star \star}(1.27-1.51)$ \\
\hline \multicolumn{4}{|l|}{ Condom use } \\
\hline \multicolumn{4}{|l|}{ No (Ref.) } \\
\hline Yes & & & $1.87^{\star \star \star}(1.80-1.95)$ \\
\hline \multicolumn{4}{|l|}{ Multiple sexual partners } \\
\hline \multicolumn{4}{|l|}{ No (Ref.) } \\
\hline Yes & & & $1.87^{\star \star *}(1.80-1.95)$ \\
\hline \multicolumn{4}{|l|}{ Wealth Index } \\
\hline Poorest & & & $0.48^{\star \star \star}(0.84-0.92)$ \\
\hline Poorer & & & $0.57^{\star \star \star}(0.54-0.60)$ \\
\hline Middle & & & $0.64^{\star \star \star}(0.61-0.67)$ \\
\hline Richer & & & $0.73^{\star * \star}(0.70-0.76)$ \\
\hline \multicolumn{4}{|l|}{ Richest (Ref.) } \\
\hline \multicolumn{4}{|l|}{ Place of residence } \\
\hline Urban & & & $0.84^{\star \star \star}(0.81-0.87)$ \\
\hline \multicolumn{4}{|l|}{ Rural (Ref.) } \\
\hline \multicolumn{4}{|l|}{ Random effect result } \\
\hline PSU variance $(95 \% \mathrm{CI})$ & $0.35(0.30-0.41)$ & $0.25(0.21-0.30)$ & $0.18(0.15-0.21)$ \\
\hline ICC & 0.0953595 & 0.0710073 & 0.0508952 \\
\hline LR test & $\chi^{2}=1464.76$ & $\chi^{2}=1095.34$ & $\chi^{2}=769.02^{\star \star \star}$ \\
\hline Wald $\chi^{2}$ & & 3427.62 & $13802.05^{\star \star \star}$ \\
\hline \multicolumn{4}{|l|}{ Model fitness } \\
\hline Log-likelihood & $-71,384.664$ & $-69,646.259$ & $-62,906.679$ \\
\hline $\mathrm{AIC}$ & $142,773.3$ & $139,298.5$ & $125,879.4$ \\
\hline$N$ & 104,398 & 104,398 & 104,398 \\
\hline Number of clusters & 1595 & 1595 & 1595 \\
\hline
\end{tabular}

${ }^{*} p<0.05 ;{ }^{* *} p<0.01 ;{ }^{* * *} p<0.001$

Ref.=Reference category; PSU: Primary Sampling Unit; ICC=Intra-Class Correlation; AIC=Akaike's Information Criterion.

Model $0=$ empty model with no explanatory variables; Model $I=$ model with only the key explanatory variable; Model IV=model with the key explanatory variable and the control variables.

prevalences, is consistent with the findings of a previous cross-sectional study in SSA (Staveteig et al., 2013). The disparities in prevalence of HIV testing among countries in SSA could be the result of disparities in programmes adopted by each country to deal with HIV/AIDS. Rwanda for example, implemented an extensive HIV/AIDS comprehensive education programme in 1986 using the radio and public health educators (Allen et al., 1991), and launched the 'treat all 
programme' in the early 2000s, later restructured (in 2016) by the Rwandan Ministry of Health to make testing cheap and more easily accessible and put all those who tested positive on treatment immediately. These, coupled with previous successes that have seen over $99 \%$ of health facilities in Rwanda providing HIV testing services, have all contributed to the higher comprehensive HIV/ AIDS Knowledge and HIV testing prevalence in Rwanda than in other countries, such as Congo $\mathrm{DR}$; this is reported to be challenged with lack of HIV testing services and inadequate testing centres, which could be a plausible explanation for its low HIV testing (Carlos et al., 2015; Nsanzimana et al., 2015; UNAIDS, 2017).

In general, the reason for the increase in HIV testing among men in SSA from $22.8 \%$ reported by Staveteig et al. (2013) to 53.5\% reported in the present study could be the general scaling up and implementation of the UNAIDS 90:90:90 programme in SSA, which sought to achieve by 2020 ( $90 \%$ of people living with HIV/AIDS knowing their status, $90 \%$ of people who know their status having access to antiretroviral therapy and at least $90 \%$ of people on treatment having a suppressed viral load) (Piot et al., 2015; Maheu-Giroux et al., 2019). Notwithstanding this, there is the need for SSA countries to further develop pragmatic health strategies (such as self-testing and mobile or workplace testing) and comprehensive education on the need to test for HIV/AIDS as this will help attain the United Nations goal of achieving 95-95-95 by the year 2030 .

The literature suggests that comprehensive knowledge of HIV/AIDS leads to positive behavioural attitudes, which in turn lead to a reduced risk of infection (Seidu et al., 2020). It is, therefore, not surprising to find that men who had no comprehensive HIV/AIDS knowledge also had lower odds of testing for HIV compared with their counterparts who had comprehensive knowledge, and this supports the findings of a previous study among youths in SSA by Asaolu et al. (2016).

Corroborating the findings of previous studies (Staveteig et al., 2013; Asaolu et al., 2016), this study found that men aged 15-19 years had lower odds of testing for HIV compared with those aged 25-29 years. A plausible reason for this could be that younger males are mostly dependent on their parents and may lack the decision-making power and the financial capability to go for HIV testing. Also, their unwillingness to go for testing may be as a result of fear, anxiety or stigma (Asante, 2013). Programmes to scale up HIV testing should therefore consider conducting periodic and mandatory HIV testing for younger men in educational settings.

This study found that those who were working had lower odds of testing for HIV, unlike the study by Kefale et al. (2020). A plausible reason for this finding could be that workers may have difficulty absenting themselves from work and find the time to spend at health centres or hospitals to test for HIV. Policymakers therefore need to intensify the provision of rapid diagnostic tests, self-test gadgets and mobile health vans to bring HIV testing to the doorstep of men, especially the working population in the sub-Saharan African region.

In support of findings of previous studies (Ziraba et al., 2011; Agha, 2012), this study found that those who were not married had the lowest odds of testing for HIV. The common practice of premarital HIV testing in many sub-Saharan African countries could be the plausible reason behind this finding. Previous studies have highlighted how HIV testing is often made mandatory for people preparing to marry in some SSA countries, including Nigeria, Ethiopia, and Cameroon so most married men have already tested for HIV (Arulogun \& Adefioye, 2010; Akoku et al., 2018; Ahmed \& Seid, 2020).

Findings from previous studies (Teshome et al., 2016; Yaya et al., 2016; Sheikh et al., 2017; Agegnehu et al., 2020) support the present finding that those with no education had the lowest odds of testing for HIV. A plausible reason for this is that people who are educated may have greater access to information on HIV testing, as well as how and where to get tested, than those who have no formal education (Agegnehu et al., 2020; Kefale et al., 2020). Another likely explanation is that individuals who have no education may lack the ability to understand the need to test for HIV (Kefale et al., 2020). Also, people who are educated may possibly get their knowledge on HIV testing from school-based HIV/AIDS prevention programmes (Kefale et al., 2020). There is the need to design public health interventions, such as creating more community health posts 
and information centres where less-educated individuals could be educated on the virus and the lifetime and economic consequences of HIV/AIDS and the importance of testing for HIV.

Furthermore, corroborating other previous studies (Yaya et al., 2016; Agegnehu et al., 2020; Kefale et al., 2020), the study found that men who were exposed to newspapers, radio, and television almost every day were more likely to test for HIV. A possible reason for this could be that those who are exposed to mass media may be exposed to educative contents that aids their understanding of HIV/AIDS, especially with its mode of acquisition and spread, available testing options and living with the virus (Kefale et al., 2020). This highlights the importance of education through mass media as a tool to significantly improve the prevalence of HIV testing in sub-Saharan African countries. The finding that men who used condoms, and also men who had multiple sexual partners, were more likely to test for HIV supports the findings of a previous cross-sectional study in Mozambique by Agha (2012). A possible reason for this is that men who use condoms and have multiple sexual partners are aware that they may be more exposed to HIV/ AIDS, and hence their willingness to go for an HIV test.

Akin to other previous studies (Agegnehu et al., 2020), the study found that men in the poorest wealth quintile had the lowest odds of testing for HIV. A possible reason for this could be that poor individuals may not be able to afford the transport costs to and from health service centres for HIV testing since these are often located far away in sub-Saharan African countries (Agha, 2012). The scaling up of self-testing and the deployment of cheap rapid diagnostic/testing kits in all parts of SSA to enable individuals to conduct their own HIV test, coupled with strategies to either reduce transport costs or provide free transport to and from health service centres for HIV testing in sub-Saharan African countries, could be steps in the right direction to improve HIV testing among the poor individuals in the communities.

Research has shown that urban residents are more likely to have adequate knowledge of HIV/ AIDS and have the self-efficacy to adhere to HIV/AIDS education and test for HIV (Yaya et al., 2016; Kefale et al., 2020). Surprisingly, the present study found that those residing in urban areas were less likely to test for HIV compared with those in rural areas. This finding contradicts the finding of previous studies (Yaya et al., 2016; Kefale et al., 2020). A possible reason for this could be the variations in geographical location, socio-cultural, and socioeconomic characteristics of the study areas.

The study had its strengths and limitations. Its main strength was its use of nationally representative data from 29 sub-Saharan African countries. The data collection technique and methodology employed by the DHS followed best practice by experienced and well-trained data collectors, resulting in a high response rate. The findings of this study can, therefore, be generalized to all men in SSA. Advanced statistical models that accounted for both individual and contextual factors were also employed. However, the study followed a cross-sectional study design and as such it was not possible to account for unobserved heterogeneity; causal interpretation cannot be deduced from the study findings. Also, the relationships established between the explanatory and dependent variables may vary over time.

In conclusion, after controlling for confounding factors, men in SSA with comprehensive knowledge of HIV/AIDS were found to be more likely to test for HIV compared with their counterparts who had no comprehensive knowledge of HIV/AIDS. To improve HIV testing among men in SSA as a crucial step towards the eradication of the virus and the attainment of the 95-95-95 by 2030 global target, this study recommends that policymakers and all stakeholders in SSA step up comprehensive HIV/AIDS knowledge education while ensuring that HIV testing services are cheap and easily accessible through the provision of self-testing kits and mobile or workplace testing programmes. Mass media could be key to facilitating this.

Acknowledgments. The authors are grateful to the MEASURE DHS project for granting free access to their original data.

Funding. This research did not receive any specific grant from funding agencies in the public, commercial or not-for-profit sectors. 
Conflicts of Interest. The authors declare that they have no conflicts of interest. There are no financial, copyright, trademarks or patent implications arising from this research and no organization has any vested interest in this research.

Ethical Approval. Publicly available survey data were used, and ethical approval for the surveys was granted by the governments of the relevant countries and the US government. Further information about DHS data usage and ethical standards are available at http://goo.gl/ny8T6X.

Author contributions. JKT: formal analysis, writing of original draft, reviewing and editing, visualization. JBF: writing of original draft, reviewing and editing. EB: methodology, formal analysis, writing of original draft, reviewing and editing. CA: formal analysis, writing of original draft, reviewing and editing. AM: writing of original draft, reviewing and editing. BOA: conceptualization, methodology, formal analysis, writing, reviewing and editing, visualization. AS: conceptualization, methodology, formal analysis, writing, reviewing and editing, visualization.

\section{References}

Aderemi TJ, Mac-Seing M, Woreta SA and Mati KA (2014) Predictors of voluntary HIV counselling and testing services utilization among people with disabilities in Addis Ababa, Ethiopia. AIDS Care 26(12), 1461-1466.

Agegnehu CD, Geremew BM, Sisay MM, Muchie KF, Engida ZT, Gudayu TW et al. (2020) Determinants of comprehensive knowledge of HIV/AIDS among reproductive age (15-49 years) women in Ethiopia: further analysis of 2016 Ethiopian Demographic and Health Survey. AIDS Research and Therapy 17(1), 1-9.

Agha S (2012) Factors associated with HIV testing and condom use in Mozambique: implications for programs. Reproductive Health 9(1), 20.

Ahmed M and Seid A (2020) Factors associated with premarital HIV testing among married women in Ethiopia. PLoS One 15(8), e0235830.

Akoku DA, Tihnje MA, Tarh EO, Tarkang EE and Mbu RE (2018). Predictors of willingness to accept pre-marital HIV testing and intention to sero-sort marital partners; risks and consequences: findings from a population-based study in Cameroon. PLoS One 13(12), e0208890.

Aliaga A and Ruilin R (2006) Cluster optimal sample size for Demographic and Health Surveys. In 7th International Conference on Teaching Statistics - ICOTS, Vol. 7, pp. 2-7.

Allen S, Lindan C, Serufilira A, Van de Perre P, Rundle AC, Nsengumuremyi F et al. (1991) Human immunodeficiency virus infection in urban Rwanda: demographic and behavioral correlates in a representative sample of childbearing women. JAMA. 266(12), 1657-1663.

Arulogun OS and Adefioye OA (2010) Attitude towards mandatory pre-marital HIV testing among unmarried youths in Ibadan northwest local government area, Nigeria. African Journal of Reproductive Health 14(1), 83-94.

Asante KO (2013) HIV/AIDS knowledge and uptake of HIV counselling and testing among undergraduate private university students in Accra, Ghana. Reproductive Health 10(1), 17.

Asaolu IO, Gunn JK, Center KE, Koss MP, Iwelunmor JI and Ehiri JE (2016) Predictors of HIV testing among youth in subSaharan Africa: a cross-sectional study. PloS One 11(10), e0164052.

Austin PC and Merlo J (2017) Intermediate and advanced topics in multilevel logistic regression analysis. Statistics in Medicine 36(20), 3257-3277.

Bwambale FM, Ssali SN, Byaruhanga S, Kalyango JN and Karamagi CA (2008) Voluntary HIV counselling and testing among men in rural western Uganda: implications for HIV prevention. BMC Public Health 8(1), 263.

Carlos S, Martínez-González MÁ, Burgueño E, López-Del Burgo C, Ruíz-Canela M, Ndarabu A et al. (2015) Misconceptions about HIV infection in Kinshasa (Democratic Republic of Congo): a case-control study on knowledge, attitudes and practices. Sexually Transmitted Infections 91(5), 334-337.

Chikwari CD, Dringus S and Ferrand RA (2018) Barriers to, and emerging strategies for, HIV testing among adolescents in sub-Saharan Africa. Current Opinion in HIV and AIDS 13(3), 257-264.

Cohen MS, Chen YQ, McCauley M, Gamble T, Hosseinipour MC, Kumarasamy N and Godbole SV (2011) Prevention of HIV-1 infection with early antiretroviral therapy. New England Journal of Medicine 365(6), 493-505.

Corsi DJ, Neuman M, Finlay JE and Subramanian S (2012) Demographic and Health Surveys: a profile. International Journal of Epidemiology 41(6), 1602-1613.

Darteh EK (2020) Individual and contextual predictors of comprehensive HIV and AIDS knowledge among young females in Ghana. African Journal of AIDS Research 19(3), 222-230.

DiCarlo AL, Mantell JE, Remien RH, Zerbe A, Morris D, Pitt B et al. (2014) 'Men usually say that HIV testing is for women': gender dynamics and perceptions of HIV testing in Lesotho. Culture Health Sexuality 16(8), 867-882.

Fauci AS and Lane HC (2020) Four decades of HIV/AIDS - much accomplished, much to do. New England Journal of Medicine 383(1), 1-4.

Frank TD, Carter A, Jahagirdar D, Biehl MH, Douwes-Schultz D, Larson SL and Abu-Raddad LJ (2019) Global, regional, and national incidence, prevalence, and mortality of HIV, 1980-2017, and forecasts to 2030, for 195 countries and 
territories: a systematic analysis for the Global Burden of Diseases, Injuries, and Risk Factors Study 2017. The Lancet HIV 6(12), e831-e859.

Frimpong JB, Budu E, Adu C, Mohammed A, Tetteh JK, Seidu AA and Ahinkorah BO (2021) Comprehensive HIV/AIDS knowledge and safer sex negotiation among adolescent girls and young women in sub-Saharan Africa. Journal of Biosocial Science, doi:10.1017/S0021932021000493.

Harichund C and Moshabela MJA (2018) Acceptability of HIV self-testing in sub-Saharan Africa: scoping study. AIDS and Behavior 22(2), 560-568.

Harichund C, Moshabela M, Kunene P and Abdool Karim Q (2019) Acceptability of HIV self-testing among men and women in KwaZulu-Natal, South Africa. Aids Care 31(2), 186-192.

Hensen B, Lewis J, Schaap A, Tembo M, Mutale W, Weiss H et al. (2015) Factors associated with HIV-testing and acceptance of an offer of home-based testing by men in rural Zambia. AIDS Behavior 19(3), 492-504.

Jewell BL, Mudimu E, Stover J, Ten Brink D, Phillips AN, Smith JA and Bansi-Matharu L (2020) Potential effects of disruption to HIV programmes in sub-Saharan Africa caused by COVID-19: results from multiple mathematical models. The Lancet HIV 7(9), e629-e640.

Kefale B, Damtie Y, Yalew M, Adane B and Arefaynie M (2020) Predictors of comprehensive knowledge of HIV/AIDS among people aged 15-49 years in Ethiopia: a multilevel analysis. HIV/AIDS (Auckland, NZ) 12, 449.

Kejela G, Oljira L, Dessie Y and Misker D (2015) Comprehensive HIV/AIDS knowledge level among out-of-school youths in WayuTuka district, Western Ethiopia. European Journal of Preventive Medicine 3(1), 11-16.

Maheu-Giroux M, Marsh K, Doyle CM, Godin A, Lanièce Delaunay C, Johnson LF et al. (2019) National HIV testing and diagnosis coverage in sub-Saharan Africa: a new modeling tool for estimating the 'first 90 ' from program and survey data. AIDS 33, S255-S269.

Merlo J, Wagner P, Ghith N and Leckie G (2016) An original stepwise multilevel logistic regression analysis of discriminatory accuracy: the case of neighbourhoods and health. PloS One 11(4), e0153778.

Muleme J, Kankya C, Ssempebwa JC, Mazeri S and Muwonge A (2017) A framework for integrating qualitative and quantitative data in knowledge, attitude, and practice studies: a case study of pesticide usage in Eastern Uganda. Frontiers in Public Health 5, 318.

Nsanzimana S, Prabhu K, McDermott H, Karita E, Forrest IJ, Drobac P et al. (2015) Improving health outcomes through concurrent HIV program scale-up and health system development in Rwanda: 20 years of experience. BMC Medicine 13, 216.

Oljira L, Berhane Y and Worku A (2013) Assessment of comprehensive HIV/AIDS knowledge level among in-school adolescents in eastern Ethiopia. Journal of the International AIDS Society 16(1), 17349.

Pandey A and Galvani A P (2019) The global burden of HIV and prospects for control. The Lancet HIV 6(12), e809-e811.

Piot P, Abdool Karim SS, Hecht R, Legido-Quigley H, Buse K, Stover J et al. (2015) Defeating AIDS: advancing global health. The Lancet 386, 171-218.

Seidu AA, Ahinkorah BO, Dadzie LK, Tetteh JK, Agbaglo E, Okyere J et al. (2020) A multi-country cross-sectional study of self-reported sexually transmitted infections among sexually active men in sub-Saharan Africa. BMC Public Health 20, 1884.

Sharma M, Ying R, Tarr G and Barnabas R (2015) Systematic review and meta-analysis of community and facility-based HIV testing to address linkage to care gaps in sub-Saharan Africa. Nature 528(7580), S77-S85.

Sheikh MT, Uddin MN and Khan JR (2017) A comprehensive analysis of trends and determinants of HIV/AIDS knowledge among the Bangladeshi women based on Bangladesh Demographic and Health Surveys, 2007-2014. Archives of Public Health 75(1), 59.

Sorensen SW, Sansom SL, Brooks JT, Marks G, Begier EM, Buchacz K et al. (2012) A mathematical model of comprehensive test-and-treat services and HIV incidence among men who have sex with men in the United States. PloS One 7(2), e29098.

Staveteig S, Wang S, Head SK, Bradley SEK and Nybro, E (2013) Demographic patterns of HIV testing uptake in subSaharan Africa. DHS Comparative Report No. 30. URL: http://dhsprogram.com/pubs/pdf/CR30/CR30.pdf (accessed 11th May 2021).

Teshome R, Youjie W, Habte E and Kasm NM (2016) Comparison and association of comprehensive HIV/AIDS knowledge and attitude towards people living with HIV/AIDS among women aged 15-49 in three east African countries: Burundi, Ethiopia and Kenya. Journal of AIDS and Clinical Research 7(04), 1-8.

United Nations General Assembly (2016) Political Declaration on HIV and AIDS: on the Fast-Track to Accelerate the Fight against HIV and to end the AIDS Epidemic by 2030. United Nations, New York. URL: https://www.unaids.org/sites/default/ files/media_asset/2016-political-declaration-HIV-AIDS_en.pdf (accessed 11th May 2021).

United Nations Programme on HIV/AIDS (2017) Rwanda Country Reports 2017. URL: https://www.unaids.org/sites/ default/files/country/documents/RWA_2017_countryreport.pdf (accessed 11th May 2021).

United Nations Programme on HIV/AIDS (2018) Knowledge is power: know your status, know your viral load. URL: -https:// www.unaids.org/sites/default/files/media_asset/jc2940_knowledge-is-power-report_en.pdf (accessed 11th May 2021). 
Von Elm E, Altman D-G, Egger M, Pocock S-J, Gøtzsche P-C, Vandenbroucke JP and Initiative S (2014) The Strengthening the Reporting of Observational Studies in Epidemiology (STROBE) statement: guidelines for reporting observational studies. International Journal of Surgery 12(12), 1495-1499

World Health Organization (2020) HIV/AIDS. URL: https://www.who.int/news-room/fac-sheets/detail/hiv-aids (accessed 11th May 2021).

Yaya S, Bishwajit G, Danhoundo G and Seydou I (2016) Extent of knowledge about HIV and its determinants among men in Bangladesh. Frontiers in Public Health 4, 246.

Yaya S, Bishwajit G, Danhoundo G, Shah V and Ekholuenetale M (2016) Trends and determinants of HIV/AIDS knowledge among women in Bangladesh. BMC Public Health 16(1), 812.

Ziraba AK, Madise NJ, Kimani JK, Oti S, Mgomella G, Matilu M and Ezeh A (2011) Determinants for HIV testing and counselling in Nairobi urban informal settlements. BMC Public Health 11(1), 663.

Cite this article: Tetteh JK, Frimpong JB, Budu E, Adu C, Mohammed A, Ahinkorah BO, and Seidu A-A (2022). Comprehensive HIV/AIDS knowledge and HIV testing among men in sub-Saharan Africa: a multilevel modelling. Journal of Biosocial Science 54, 975-990. https://doi.org/10.1017/S0021932021000560 